\title{
Research on the Effect Mechanism of Young Teachers' Self-efficacy on Work Attitude and Performance
}

\author{
Xiaojuan ZENG ${ }^{1}$, \\ ${ }^{1}$ Northeastern University at Qinhuangdao \\ Qinhuangdao 066004 \\ Hebei,China
}

\author{
Chun LIU ${ }^{2}$ \\ ${ }^{2}$ Higher Education Science Institute \\ Dalian University, Dalian 116622 \\ Liaoning,China
}

\begin{abstract}
Self-efficacy is the core variable to inspire human motivation and behavior, and the self-efficacy of young teachers can affect their attitude toward work, behavior and performance. Through an empirical study of 321 young teachers (samples), the relationship of teachers' self-efficacy with working attitude and performance was discussed. The results showed that self-efficacy was positively correlated with work satisfaction and performance, but negatively correlated with turnover intention; the peripheral and teaching performances were improved and turnover intention was reduced through positively responding to the intermediary role of strategies. This provides a new research perspective for the humanistic management of college and university teachers.
\end{abstract}

Keywords: Young Teachers; Self-efficacy; Work Performance; Work Satisfaction; Turnover Intention

\section{INTRODUCTION}

Self-efficacy is a core concept of social cognitive theory, proposed by American psychologist Bandura. It refers to the faith of people on their own behavioral competence for completing a task or work [1]. Teachers' selfefficacy refers to the perception and belief of teachers on their own ability to complete education, teaching and scientific research tasks. In China, empirical researches on the effect of the self-efficacy of young teachers in colleges and universities on working attitude, performance, and behavior remain to be insufficient yet now. Studying the self-efficacy of young teachers is of important practical significance to scientific and humanistic management of colleges and universities.

\section{Literature review and research hypothesis}

In the researches on the effect results of selfefficacy, working attitude and performance are mainly concentrated. The individuals with high self-efficacy will positively expect the behavioral results and then show a positive working attitude, because they believe they can control tasks [1]. Judge and Bono, by making a meta-analysis, found that the work attitude and performance of individuals were directly affected by self-efficacy generally [2]. McDonald, using technical personnel as the research objects, studied and found that selfefficacy was significantly positively correlated with work satisfaction and commitment level, but significantly negatively correlated with turnover intention and laziness in work [3]. Changqin LIU et al empirically studied and found that in enterprises, the managers with high self-efficacy were not only with high work satisfaction and involvement, but also with good management effects and innovations [4]. 
In the researches on the relationship between self-efficacy and performance, the results proved that the self-efficacy was one of the best predictors to forecast performance. Sadri and Robertson made a meta-analysis on the studies of the relationship of self-efficacy with work performance and related behaviors, and the result showed that the correlation of selfefficacy with work performance was 0.40 , but 0.34 with behavior choice and intention; the correlation of self-efficacy with actual work performance was 0.60 in simulation studies, but reached 0.85 to the highest, much higher than 0.37 [5] in field researches. Stajkovic and Luthans, in 1998, made a meta-analysis on previous studies, and the results showed that the correlation of self-efficacy with work performance was 0.38 , similar to the result of Sadri and Robertson; the correlation in simulation studies was higher than that in field researches [6]. Wood and Bandura et al, through a field research, found that the correlation of a manager's self-efficacy and work performance was in 0.26 0.40 [7]. China's scholar Changqin LIU et al studied the correlation of a manager's self-efficacy and work performance was 0.51 [4].

In addition, related studies found that selfefficacy played an indirect effect on working attitude and performance through the application of positive strategies.

\section{Research and measurement}

\subsection{Participants}

321 young teachers under the age of 40 years old were chosen from more than 10 colleges and universities in Beijing, Shanghai, and Hebei as valid samples: 158 male teachers and 163 female teachers; 58 unmarried teachers, 254 married teachers, and 9 divorced teachers; 30 with bachelor degree, 141 with 141 master degree, and 150 with doctoral degree; 44 teaching assistants, 180 lecturers, 189 associate professors, and 8 professors; 166 graduated from science programs and 155 from liberal arts programs; 86 from research-oriented universities, 155 from ordinary colleges and universities, and 80 from vocational colleges. From the basic conditions of the investigated teachers, samples included the teachers with different demographic characteristics, and also were randomly selected, so that the reliability of analysis results was guaranteed.

\subsection{The research tools}

\subsubsection{Self-efficacy questionnaire}

Five-point scoring method was applied to questionnaire. From "complete inconformity" to "complete conformity", higher scores meant higher self-efficacy.

\subsubsection{Coping-strategies questionnaire}

Five-point scoring method was applied to questionnaire. From "never" to "always", higher scores meant more positive strategies to be applied.

\subsubsection{Work satisfaction questionnaire}

Five-point scoring method was applied to questionnaire. From "very dissatisfied" to "very satisfied", higher scores meant higher satisfaction with organization.

\subsubsection{Work performance questionnaire}

Five-point scoring method was applied to questionnaire. From "complete inconformity" to "complete conformity", higher scores meant higher work performance.

\subsubsection{Turnover intention questionnaire}

Five-point scoring method was applied to questionnaire. From "complete inconformity" to "complete conformity", higher scores meant higher turnover intention.

\subsection{Research steps}

The reliability and validity of the questionnaire on the prediction of "the effect of the selfefficacy of young teachers in colleges and universities on working attitudes and performance" were verified and the items in the questionnaire were purified to generate a formal questionnaire. The reliability and validity of 321 teachers were tested, and also descriptive statistics analysis, correlation analysis and regression analysis were conducted to explore 
the effect of self-efficacy on working attitude and performance through coping strategies.

\section{Research results and analysis}

\subsection{Correlation analysis}

The data of 321 teachers was descriptively statistically analyzed. The data in table 1 showed that these teachers' self-efficacy
(M=3.882, $\mathrm{SD}=0.629$, positive coping strategy $(\mathrm{M}=3.963, \mathrm{SD}=0.621)$, peripheral performance $(\mathrm{M}=4.000, \quad \mathrm{SD}=0.593), \quad$ and teaching performance $(\mathrm{M}=3.829, \mathrm{SD}=3.829)$ were high, work satisfaction $(\mathrm{M}=3.066, \mathrm{SD}=3.066)$, and scientific research performance $(\mathrm{M}=3.074$, $\mathrm{SD}=0.838$ ) were medium, and turnover intention $(\mathrm{M}=2.068, \mathrm{SD}=2.068)$ was low.

Table 1: Analysis on the correlation of self-efficacy with working attitude and performance variable

\begin{tabular}{|c|c|c|c|c|c|c|c|c|}
\hline Variable & $\begin{array}{l}\text { Mean } \\
(\mathrm{M})\end{array}$ & $\begin{array}{c}\text { Standard } \\
\text { Deviation (SD) }\end{array}$ & 1 & 2 & 3 & 4 & 5 & 6 \\
\hline 1. Self-efficacy & 3.882 & .629 & & & & & & \\
\hline $\begin{array}{l}2 \text { Positive coping } \\
\text { strategy }\end{array}$ & 3.963 & .621 & $.508 * * *$ & & & & & \\
\hline 3. Work satisfaction & 3.066 & .696 & $.210 * * *$ & $.250 * * *$ & & & & \\
\hline $\begin{array}{l}\text { 4. Peripheral } \\
\text { performance }\end{array}$ & 4.000 & .573 & $.459 * * *$ & $.475 * * *$ & $.137 *$ & & & \\
\hline $\begin{array}{l}5 . \text { Teaching } \\
\text { performance }\end{array}$ & 3.829 & .647 & $.508 * * *$ & $.480 * * *$ & $.148 * *$ & $.610 * * *$ & & \\
\hline $\begin{array}{l}\text { 6. Scientific research } \\
\text { performance }\end{array}$ & 3.074 & .838 & $.247 * * *$ & $.270 * * *$ & $.287 * * *$ & $.397 * * *$ & $.344 * * *$ & \\
\hline 7. Turnover intention & 2.068 & .792 & $-.286 * * *$ & $-.370 * * *$ & $-.459 * * *$ & $-.310 * * *$ & $-.241 * * *$ & $-.226 * * *$ \\
\hline
\end{tabular}

The correlation analysis results showed that self-efficacy was positively correlated with ping strategy, work satisfaction and performance $(\mathrm{r}=0.210 \sim 0.508, \quad \mathrm{p}<0.001)$, but negatively correlated with turnover intention $(\mathrm{r}=-0.286$, $\mathrm{p}<0.001)$. Self-efficacy was significantly positively correlated with work satisfaction $(\mathrm{r}=0.210, \mathrm{p}<0.001)$.

Self-efficacy was significantly positively correlated with the three dimensions of work performance $(\mathrm{r}=0.247 \sim 0.508, \mathrm{p}<0.001)$. The correlation coefficients of the young teachers' self-efficacy with peripheral and teaching performances were consistent with Stajkovic and Luthans' meta-analysis result, Wood and Bandura's research result, and Changqin LIU's empirical result [4].

\subsection{The test of the intermediary role of coping strategy}

To test the intermediary role, the viewpoint of Baron and Kenny was applied. They thought 4 conditions should be available for testing whether the intermediary role existed: (1) independent variable and mediating variable were significantly correlated; (2) intermediary variable and dependent variable were significantly correlated; (3) independent variable and dependent variable were significantly correlated; (4) the correlation between dependent and independent variables was significantly reduced once intermediary variable was introduced to the equation [16]. To prevent multi-collinearity problem, the standard $($ Tol $<0.1, \mathrm{VIF}<10)$ was applied together to the test [17].

4.2.1 Testing the intermediary role of coping strategy on the relationship between selfefficacy and work performance

The intermediary role of coping strategy on the relationship between self-efficacy and periphery performance was tested. The first regression equation showed that the regression effect of coping strategy on the self-efficacy was significant was significant (equation's $\mathrm{F}=110.883$, Sig<0.001). The second regression equation showed that the regression effect of coping strategy on periphery performance was significant (equation's F=92.722, Sig<0.001). The first step of the third regression equation 
showed that the regression effect of periphery performance on self-efficacy was significant (equation's $\mathrm{F}=85.209$, Sig<0.001), but the absolute value of the regression coefficient of self-efficacy was reduced from 0.419 to 0.268 and the regression equation coefficient increased by $8.1 \%$, after self-efficacy and coping strategy were added simultaneously, suggesting selfefficacy improved the periphery performance through the intermediary role of coping strategy. 4.2.2 Testing the intermediary role of coping strategy on the relationship between selfefficacy and working attitude
Using self-efficacy as the independent variables, coping strategy as the intermediary variable, and turnover intention as the dependent variable, the regression effect of coping strategy on selfefficacy was analyzed, and then the regression effect of turnover intention on coping strategy was analyzed, and finally the regression effect of turnover intention on coping strategy and self-efficacy was analyzed. The statistics showed that the multi-collinearity and sequence related problems did not exist in the regression model.

Table 2: The test of the intermediary role of copying strategy on the relationship between self-efficacy and turnover intention

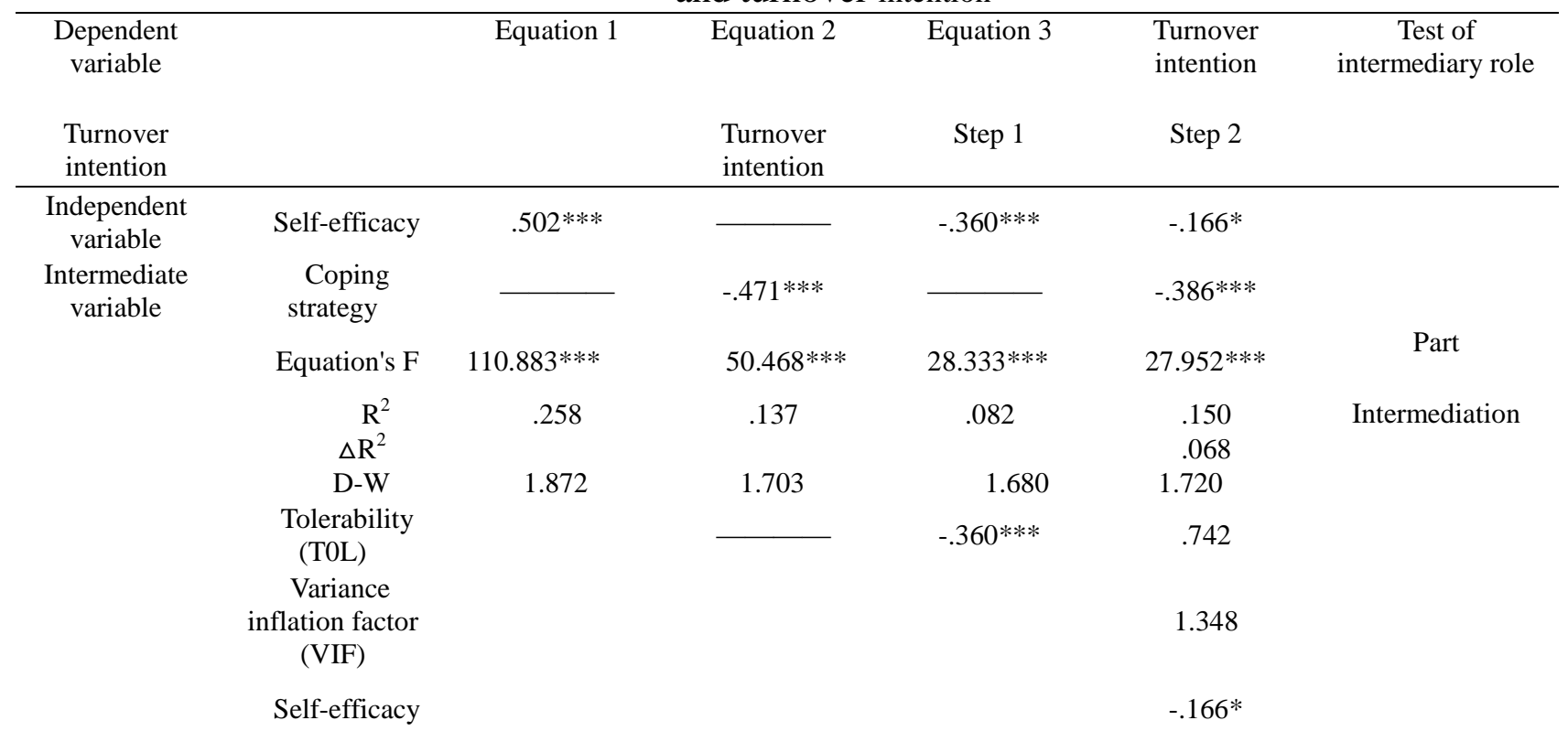

The first regression equation in table 2 showed that the regression effect of coping strategy on self-efficacy was significant (equation's F=110.883, Sig $<0.001$ ); the second regression equation showed that the regression effect of turnover intention on coping strategy was significant (equation's $\mathrm{F}=50.468$, Sig $<0.001)$. Step 1 of third regression equation of showed that the regression effect of turnover intention on coping strategy was significant (equation's F=28.333, Sig<0.001); the absolute value of the regression coefficient of selfefficacy was reduced from 0.360 to 0.166 and reached the significant level after self-efficacy and coping strategy were added simultaneously in step 2, and the determination coefficient of the regression equation increased by $6.8 \%$. The results showed that coping strategy partially played an intermediary role in the effect of selfefficacy on turnover intention.

\section{Conclusion}

Bandura's point of view was supported by the results of this paper. The conclusion shows that under the background of Chinese society and culture, young teachers' self-efficacy plays a significant effect on working attitude and 
performance. This paper can provide a beneficial reference for China's colleges and universities in the heart-oriented management of human resources.

\section{Acknowledgement}

This paper aided financially by the Education Science "12th five-year plan" Project of Liaoning Province in 2015 (No.JG15CB171), and the Scientific Research Fund Project of Northeastern University at Qinhuangdao (no.XNR201402).

\section{References}

[1] Bandura A. Self-efficacy: The exercise of control [M]. New York: Freeman, 1997.

[2] Judge T A, Bono J E. Relationship of Core Self-Evaluations Traits-Self-Esteem, Generalized Self-Efficacy, Locus of Control, and Emotional Stability-With Job Satisfaction and Job Performance: A Metaanalysis [J]. Journal of Applied Psychology, 2001, 86 (1): 80-92.

[3] McDonald T, Siegall M. The Effects of Technological Self-efficacy and Job Focus on Job Performance, Attitudes, and Withdrawal Behaviors $[\mathrm{J}]$. Journal of Psychology, 1992, 126 (5): 465-475.

[4] Changqin LU, Wenquan LING, Liluo FANG. Study on the Relationship between Management self-efficacy and managers' working attitude $[\mathrm{J}]$. Journal of Beijing university (natural science edition), 2006 (2): 275-279.

[5] Sadri G, Robertson I T. Self-efficacy and Work-related Behavior: A Review and Meta-analysis [J]. Applied Psychology: An International Review, 1993, 42 (2): 139-152.

[6] Stajkovic A D, Luthans F. Self-Efficacy and Work Related Performance : A MetaAnalysis [J]. Psychological Bulletin, 1998, 24 (2): 240-261.
[7] Wood R E, Bandura A. Impact of Conceptions of Ability on Self-Regulatory Mechanisms and Complex Decision Making [J]. Journal of Personality and Social Psychology. 1989, 56 (3): 407-415.

[8] Jex S M, Bliese P D, Buzzell S. The Impact of Self-efficacy on Stressor-strain Relations Coping Style as an Explanatory Mechanism[J] . Journal of Applied Psychology, 2001, (3): 401-409.

[9] Haiyan Wei. Exploratory Study on the Working Dynamic Behaviors of Developers [D]. Shanghai: Fudan University, 2007.

[10]Zhiping YANG, Wei WANG. Work Evaluation-Organizational Diagnosis and Practical Research Scale [M]. Beijing: China Light Industry Press, 2004.

[11]Zhijin ZHOU, Xinchen ZHU, Yilan WANG, et al. Investigation and Analysis on University Teachers' Job Performance and Affecting Factors [J]. Journal of Higher Engineering Education Research, 2009, (2): 111-115.

[12]Jian HU, Yan MO. An Empirical Analysis on the Relationship between University Teachers' work values and task performance [J]. Journal of management science, and science and technology, 2004, (12): 114-117.

[13]Farh J L, Tsui A S, Xin K. The Influence of Relational Demography and Guanxi: the Chinese Case [J]. Organizational Science, 1998, (4): 471-488.

[14]Ozer E M, Bandura A. Mechanisms Governing Empowerment Effects: A SelfEfficacy Analysis [J]. Journal of Personality and Social Psychology, 1990, 58 (3): 472486.

[15]Gist M S. Self-efficacy: Implications for Organizational Behavior and Human Resource Management [J]. Academy of Management Review, 1987, 12 (3): 472-485. 
[16]Baron R M, Kenny D. The Moderatormediator Variable Distinction in Social Psychological Research: Conceptual, Strategic and Statistical Considerations [J]. Journal of Personality and Social Psychology, 1986, (6): 1173-1182.
[17]Qing-guo MA. Management Statistics [M]. Beijing: Science Press, 2010.

[18]Bandura A. Self-Efficacy in Changing Societies [M]. Cambridge University Press, 1995. 